\title{
ANALISIS LALULINTAS PERTEMUAN JALAN RAYA DENGAN LINTASAN KERETA API JALAN URIP SUMOHARJO DI SURAKARTA
}

\author{
Suwardi \\ Jurusan Teknik Sipil, Fakultas Teknik, Universitas Muhammadiyah Surakarta \\ Jl. A. Yani Pabelan Kartosuro Tromol Pos 1 Telp. (0271)71741 Pes.221 Fax. (0271)715448 \\ Hp. 08122638174, home 0271 727508; e-mail: isma_chan@yahoo.co.id
}

\begin{abstract}
Urip Sumoharjo street is represent main road in Surakarta town. The Road which its very solid often happened when there is train which pass by quickly, because the road there is crossed train trajectory a piece of by way is great. When the train pass, the road happened very long queue. From above mentioned problem hence needing analysis about traffic characteristic which its about train trajectory. With analysis meant to give input all related side, so that the road do not happened queue and jam. Target of research is to knowing level service, to analysis the big delay, queue, the big loss when train moment pass. The method is used analytical discription. Result of analysis can be concluded as follows: service level of Urip Somoharja street are mean $\mathrm{C}$ and $\mathrm{B}$, the delay train moment pass by quickly mean 178.85 second, amount of queue southerly mean $36.5 \mathrm{smp} /$ trajectory, northwards 39.0 smp/trajectory. Amount of delay north and south are $239.34 \mathrm{smp}$ hour/day or $86162.4 \mathrm{smp}$ hour/year. The loss of time if calculated with rupiah equal is Rp. 3.446.498.000,00/year, loss of fuel Rp. 39.317.400,00/year, loss of fuel and time equal to Rp. 3.485. 815. 400,00 / year. In range of time 10 loss year counted Rp. 34.858.154.000,00/10 year. So that time has come at trajectory woke up with fly over.
\end{abstract}

Keywords: Delay, Queue, Trajectory Train.

\begin{abstract}
ABSTRAK
Jalan Urip Sumoharjo merupakan jalan utama di kota Surakarta. Jalan yang lalulintasnya sangat padat tersebut sering terjadi kemacetan pada waktu ada kereta api yang melintas, karena jalan tersebut ada lintasan kereta api yang menyilang sebidang dengan jalan raya. Pada waktu kereta api melintas terjadi antrian yang sangat panjang. Dari masalah tersebut di atas maka perlu analisis tentang karakteristik lalulintas yang kaitannya dengan lintasan kereta api. Dengan analisis dimaksudkan untuk memberi masukan semua pihak yang terkait, sehingga jalan tersebut tidak terjadi kemacetan dan antrian. Tujuan penelitian adalah: mengetahui tingkat pelayanan, menganalisis besar tundaan (delay), antrian, besar kerugian saat kereta api melintas. Metode yang digunakan diskriptis analitis. Hasil analisis dapat disimpulkan sebagai berikut: tingkat pelayanan Jalan Urip Somoharja rata-rata C dan B, besar tundaan (delay) saat kereta api melintas rata-rata 178.85 detik, jumlah antrian ke arah selatan rata-rata 36.5 smp/lintasan, ke arah utara 39.0 smp/lintasan. Jumlah Tundaan ke utara dan ke selatan 239.34 smp jam/ hari atau $86162.4 \mathrm{smp}$ jam/tahun. Kerugian waktu bila dihitung dengan rupiah sebesar Rp. 3.446.498.000,00/tahun, kerugian BBM Rp. 39.317.400,00/tahun, kerugian waktu dan BBM sebesar Rp. 3.485.815.400,00/tahun. Dalam kurun waktu 10 tahun kerugian sebanyak Rp. 34.858.154.000,00/10 tahun. Sehingga sudah saatnya pada perlintasan dibangun Fly Over.
\end{abstract}

Kata Kunci: Tundaan, Antrian, Lintasan Kereta Api. 


\section{PENDAHULUAN}

Jalan Urip Somoharjo merupakan jalan utama di kota Surakarta. Ruas jalan tersebut membentang ke arah Utara dan Selatan di tengah kota surakarta yang lalulintasnya sangat padat. Karena jalan tersebut merupakan akses masuk dan keluar kota Surakarta. Jalan yang lalulintasnya sangat padat tersebut sering terjadi kemacetan pada waktu ada kereta api yang melintas, karena jalan tersebut ada lintasan kereta api yang menyilang sebidang dengan jalan raya. Pada waktu kereta api menyilang akan terjadi antrian yang sangat panjang baik dari arah timur maupun arah dari Barat. Dari masalah tersebut di atas maka perlu adanya analisis tentang karakteristik lalulintas yang kaitannya dengan lintasan kereta api. Dengan analisis lalulintas ini dimaksudkan untuk memberi masukan semua pihak yang terkait sehingga pada yang masa yang akan datang ada solusi sehingga jalan tersebut tidak terjadi kemacetan dan antrian yang sangat panjang. Karena dengan adanya tundaan waktu perjalanan semua aktivitas menjadi terganggu.

Dari masalah tersebut di atas dapat dirumuskan sebagai berikut: seberapa besar tundaan (delay), jumlah antrian, besar kerugian saat kereta api melintas dan tingkat pelayanan Jalan Urip Sumoharjo Surakarta. Tujuan penelitian adalah: menganalisis tundaan (delay), jumlah antrian, besar kerugian saat kereta api melintas dan tingkat pelayanan Jalan Urip Somoharja Surakarta. Manfaat penelitian sebagai masukan pada instansi terkait untuk acuan dalam perencanaan dan pembangunan lintasan, yang selanjutnya tidak akan menimbulkan kemacetan pada lintasan, khususnya pada lintasan kereta api Jalan Urip Sumoharjo Surakarta

\section{TINJAUAN PUSTAKA}

Kapasitas jalan adalah jumlah kendaraan maksimum yang dapat melewati pada suatu ruas jalan atau seluruh jalur jalan, selama jangka waktu tertentu dan dalam keadaan jalan serta lalulintas yang tertentu pula. Menurut Manual Kapasitas Jalan Indonesia [MKJI, 1996] besarnya kapasitas dipengaruhi oleh kapasitas dasar, faktor penyesuaian kapasitas akibat lebar jalur lalu lintas, faktor penyesuaian kapasitas akibat pemisahan arah serta faktor penyesuaian kapasitas akibat hambatan samping. Maka penentuan kapasitas pada kondisi sesungguhnya dapat dihitung dengan rumus:

$$
\mathrm{C}=\mathrm{Co} \times \mathrm{FCW} \times \mathrm{FC}_{\mathrm{SP}} \times \mathrm{FC}_{\mathrm{SF}} \times \mathrm{FC}_{\mathrm{CS}}
$$

dengan:

C $\quad=$ kapasitas (smp/jam)

Co $\quad=$ kapasitas dasar (smp/jam) 
$\mathrm{FCw}=$ faktor penyesuaian akibat lebar jalur lalu lintas

$\mathrm{FC}_{\mathrm{SP}} \quad=$ faktor penyesuaian akibat pemisahan

$\mathrm{FC}_{\mathrm{SF}} \quad$ = faktor penyesuaian hambatan samping

$\mathrm{FC}_{\mathrm{CS}} \quad=$ faktor penyesuaian ukuran kota

Kecepatan rata-rata waktu adalah rata-rata aritmatik dari kecepatan kendaraan yang melewati sebuah titik selama interval waktu yang ditentukan. Dengan rumus seperti:

$$
\overline{\mathrm{Ut}}=\frac{1}{\mathrm{n}} \Sigma \overline{\mathrm{U}}
$$

dengan:

$$
\begin{array}{ll}
\overline{\mathrm{Ut}} & =\text { time mean speed, } \text { kecepatan rata-rata waktu }(\mathrm{km} / \mathrm{jam}) \\
\mathrm{n} & =\text { banyak data } \\
\Sigma \mathrm{U} & =\text { kecepatan rata-rata }(\mathrm{km} / \mathrm{jam})
\end{array}
$$

Volume lalulintas adalah jumlah kendaraan yang melewati suatu titik per satuan waktu pada lokasi tertentu. Untuk mengukur jumlah arus lalulintas, biasanya dinyatakan dalam kendaraan per hari, satuan mobil penumpang per jam, kendaraan per menit [Manual Kapasitas Jalan Indonesia, 1996].

$$
\text { V = MC. emp + LV. emp + HV. Emp }
$$

dengan:

$$
\begin{array}{lll}
\mathrm{MC} & =\text { sepeda Motor } & =0,25 \\
\mathrm{LV} & =\text { mobil penumpang } & =1,00 \\
\mathrm{HV} & =\text { kendaraan berat } & =1,20 \\
\mathrm{~V} & =\text { volume lalulintas } &
\end{array}
$$

Kepadatan adalah jumlah kendaraan per satuan panjang jalan tertentu. Satuannya adalah kendaraan per kilomter.

$$
\text { Kepadatan }=\mathrm{D}=\frac{\text { jumlah rata }- \text { rata kendaraan melewati } \mathrm{x}}{\mathrm{X}}
$$

dengan:

$\mathrm{D} \quad=$ kepadatan, jumlah kendaraan yang melewati panjang tertentu dari suatu jalan (kend./km)

$\mathrm{X} \quad=$ panjang jalan $(\mathrm{km})$ 
Kepadatan juga sama dengan volume dibagi dengan kecepatan ruang waktu (space mean speed), seperti pada persamaan berikut:

$$
\mathrm{D}=\frac{\mathrm{V}}{\mathrm{SMS}}
$$

dengan:

$\mathrm{D} \quad=$ kepadatan $($ kendaraan $/ \mathrm{km})$

$\mathrm{V}=$ volume $($ kendaraan $/ \mathrm{km})$

SMS = space mean speed $(\mathrm{km} / \mathrm{jam})$

Derajat kejenuhan didefinisikan sebagai rasio arus terhadap kapasitas, digunakan sebagai faktor utama dalam penentuan tingkat kinerja simpang dan segmen jalan. Nilai derajat kejenuhan menunjukkan apakah segmen jalan tersebut mempunyai masalah kapasitas atau tidak.

$$
\mathrm{DS}=\frac{\mathrm{Q}}{\mathrm{C}}
$$

(Sumber: Manual Kapasitas Jalan Indonesia)

dengan:

DS = derajat kejenuhan

C $\quad=$ kapasitas $(\mathrm{smp} / \mathrm{jam})$

Q $\quad=$ arus lalulintas (smp/jam)

Tingkat pelayanan jalan adalah suatu ukuran kualitas yang menguraikan kondisi operasional lalulintas dan tanggapan dari pengemudi yang diperlukan untuk menaksir derajat kepadatan lalulintas pada fasilitas jalan raya.

Tundaan adalah waktu yang hilang dimana lalulintas terganggu oleh beberapa elemen. Tundaan akibat henti (stoped delay) adalah tundaan yang terjadi pada kendaraan dengan kendaraan tearsebut berada dalam kondisi benar-benar berhenti pada kondisi mesain hidup (stasioner). Kondisi ini bila berlangsung lama akan mengakibatkan suatu kemacetan (kongestion). Penundaan mencerminkan waktu yang tidak produktif dan bila dinilai dengan uang, maka hal ini menunjukan jumlah biaya yang harus dibayar masyarakat karena memiliki jalan yang tidak memadai [Hobbs, 1979].

Tundaan dalam MKJI disebutkan merupakan waktu tempuh tambahan yang diperlukan untuk melalui simpang apabila dibandingkan lintasan tanpa melalui simpang. Tundaan terdiri dari tundaan lalulintas dan tundaan geometrik. Tundaan lalulintas (Vehicle Interaction Delay) adalah waktu menunggu yang disebabkan oleh interaksi lalulintas dengan 
gerakan lalulintas yang bertentangan. Tundaan geometrik (geometrik delay) adalah disebabkan oleh keterlambatan dan percepatan kendaraan yang membelok pada simpang atau atau yang terhenti oleh lampu merah. Total tundaan yang diperhitungkan termasuk geometrik delai dan Vehicle Interaction Delay.

Penundan karena berhenti menimbulkan selisih waktu antara kecepatan perjalanan (journey speed) dan kecepatan bergerak (running speed). Tundaan dapat dirumuskan sebagai berikut:

$$
\mathrm{ts}=\mathrm{t}_{2}-\mathrm{t}_{1}
$$

dengan:

ts $\quad=$ tundaan (detik)

$\mathrm{t}_{2} \quad=$ waktu tempuh saat palang ditutup (detik)

$\mathrm{t}_{1} \quad=$ waktu tempuh saat palang dibuka (detik)

Menurut Priyanto dalam prayogo (1999) menyebutkan dalam melakukan pengamaytan dari kondisi antrian kendaraan, akan terlihat bahwa pengemudi kendaraan akan menghentikan kendaraannya dengan suatu jarak yang bervariasi dari stop line sampai kendaraan terakhir dari antrian. Panjang antrian diukur dimulai saat pintu lintasan ditutup sampai lintasan dibuka, untuk menghitung panjang antrian adalah sebagai berikut:

$$
\mathrm{NQ}=\sum \mathrm{n} / \mathrm{n}
$$

dengan:

NQ = jumlah antrian rata-rata (smp)

$\sum \mathrm{n} \quad=$ jumlah keseluruhan kendaraan dalam antrian (smp)

$\mathrm{N} \quad=$ jumlah lintasan ditutup

Kebutuhan Bahan bakar Minyak:

$$
\text { Basic Fuel }=0,0297 . \mathrm{V}^{2}-3,3526 . \mathrm{V}+153,33 \text { liter/1000km }
$$

(Sumber: LAPI ITB)

\section{METODE PENELITIAN}

Untuk mendapatkan data sampai pada proses analisis, peneliti akan menggali data yang meliputi observasi untuk menentukan seting fisik dan lingkungan sekitarnya. Yang selanjutnya diikuti pengumpulan data sekunder dan data primer. Penelitian dilakukan di jalan Urip Sumoharjo Surakarta. Dari data primer (hasil survei) dan data sekunder dianalisis. Dari analisis tersebut akan didapatkan, volume lalulintas dibagi kapasitas (Q/C), kecepatan, 
tundaan, panjang antrian dan kerugian waktu. Kerugian bila dinilai dengan uang dan kerugian bahan bakar akibat adanya lintasan kereta api serta berapa tahun bila dibuat fly over.

\section{ANALISIS DAN PEMBAHASAN}

Kapasitas Jalan Jl. Urip Sumoharjo

$$
\begin{array}{ll}
\mathrm{Co} & =3000 \mathrm{smp} \\
\mathrm{FC}_{\mathrm{w}} & =1,00 \\
\mathrm{FC}_{\mathrm{sf}} & =\mathrm{I}, 00 \\
\mathrm{FC}_{\mathrm{cs}} & =0,84 \\
\mathrm{FC}_{\mathrm{sp}} & =0,94
\end{array}
$$

$$
\begin{gathered}
\mathrm{C}=\mathrm{Co}_{\mathrm{N}} \mathrm{FC}_{\mathrm{w}} \times \mathrm{FC}_{\mathrm{sp}} \times \mathrm{FC}_{\mathrm{sf}} \times \mathrm{FC}_{\mathrm{cs}} \\
\mathrm{C}=3000 \times 1,00 \times 1,00 \times 0,84 \times 0,94=2368,8 \mathrm{smp} / \mathrm{jam}
\end{gathered}
$$

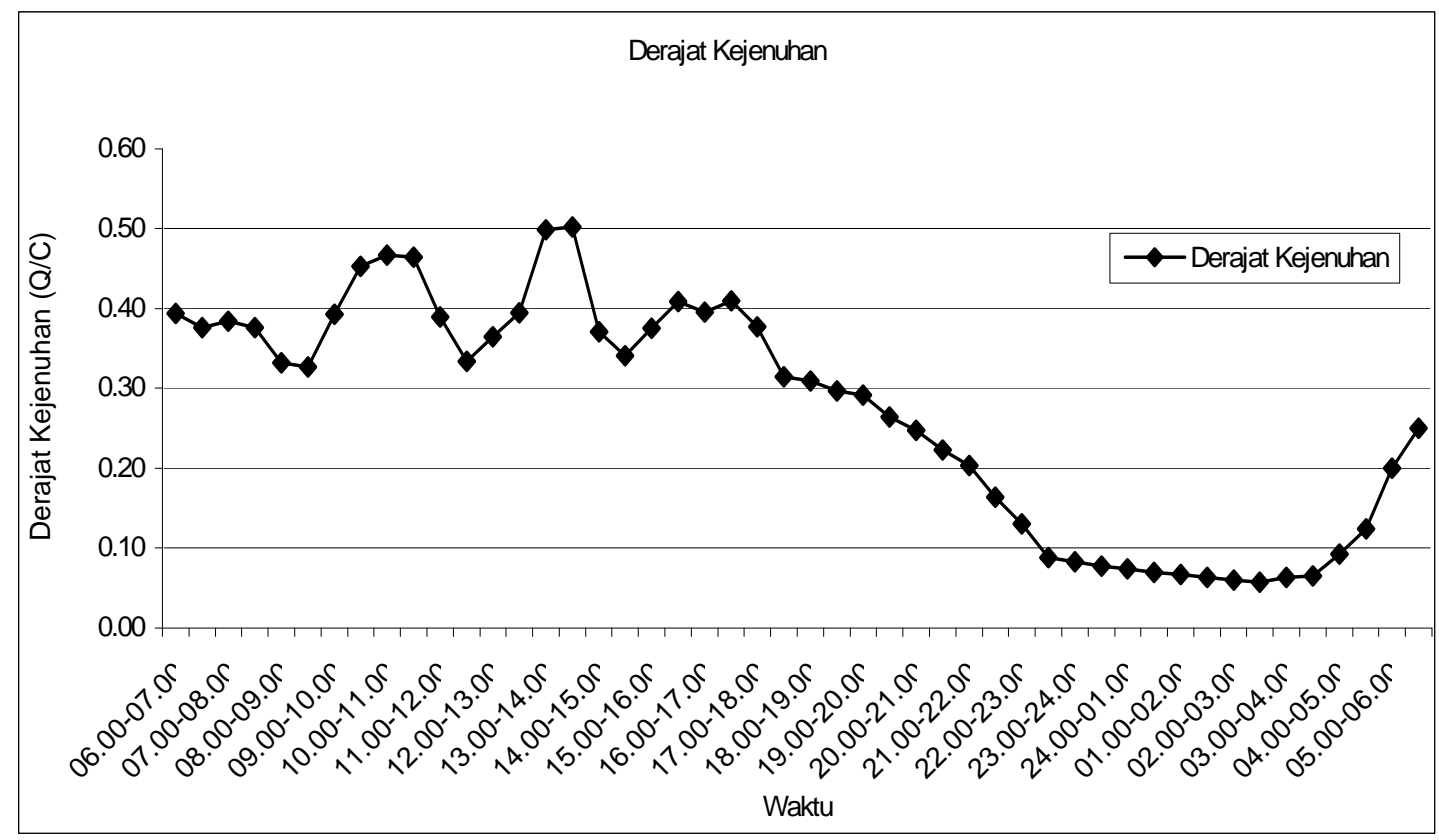

Gambar 1. Derajat kejenuhan Jalan Urip Sumoharjo.

Gambar 1 menunjukkan bahwa jalan urip Sumoharjo pada waktu siang hari ratarata tingkat pelayanan $\mathrm{C}$, waktu malam hari rata-rata tingkat pelayanan $\mathrm{B}$. 


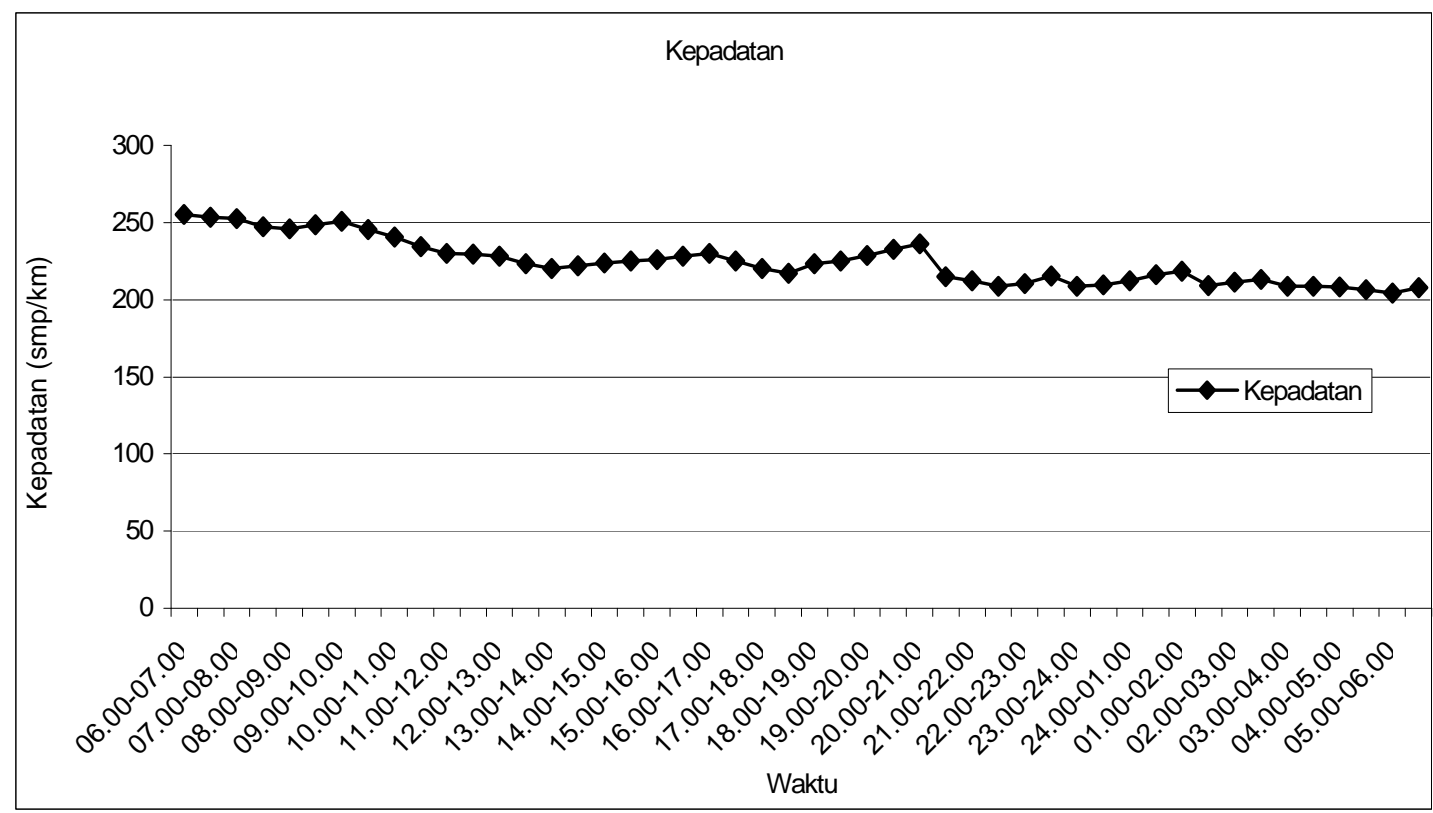

Gambar 2. Tinglat kepadatan Jalan Urip Sumoharjo.

Gambar 2 menunjukan Tingkat kepadatan pada waktu siang hari antara 68,3 sampai 112,4 kend/km, pada waktu malam hari antara 12,2 sampai $69 \mathrm{kend} / \mathrm{km}$.

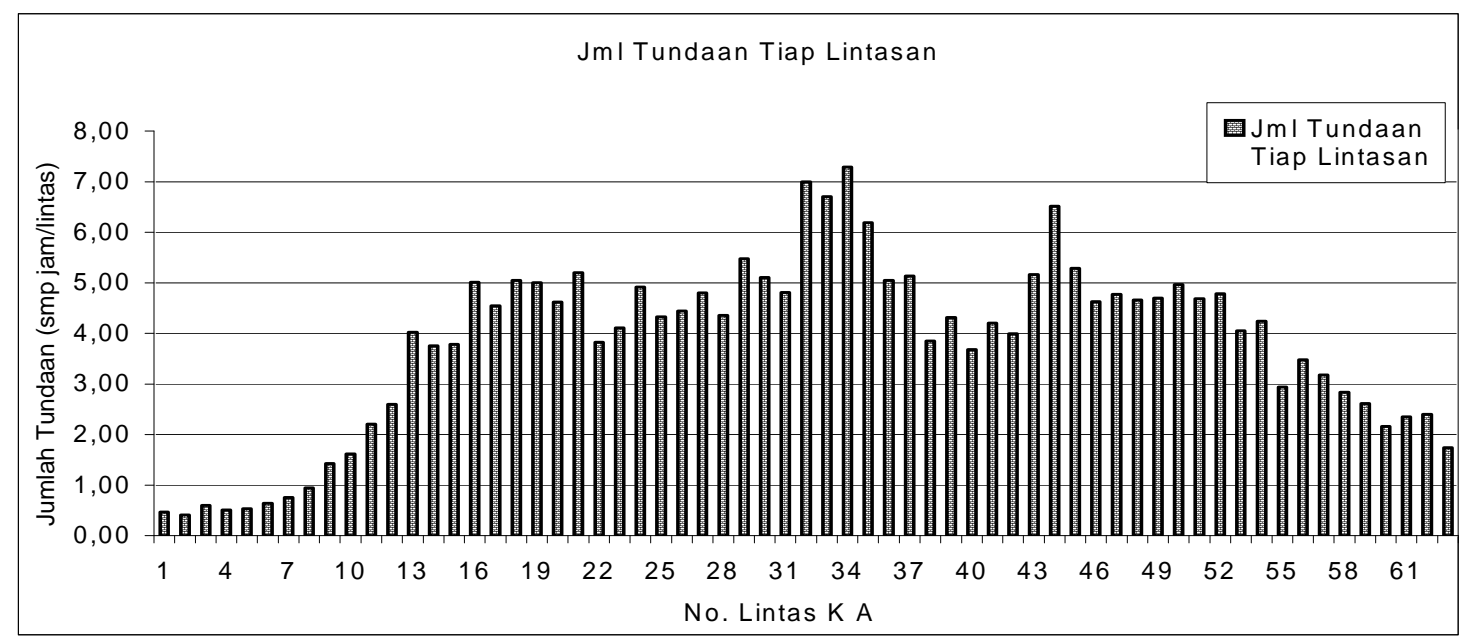

Gambar 3. Tundaan kendaraan tiap-tiap kereta api melintas.

Gambar 3 menunjukan bahwa jumlah tundaan dua arah yaitu arah Utara dan arah Selatan $=149,01+90,33=239,34 \mathrm{smp}$ jam/hari. Tundaan dalam satu tahun $=360 \times 239,34$ 
$=86162,4 \mathrm{smp}$ jam/tahun. Asumsi 1 satuan mobil penumpang jumlah penumpang 4 penumpang. Asumsi semua yang lewat dalam 1 jam dinilai dengan uang Rp. 10.000,00. Jumlah kerugian dalam 1 tahun akibat lintasan kereta api $=86162,4 \times 4$ orang $\mathrm{x}$ Rp. $10.000,00=$ Rp. 3.446.498.000,00

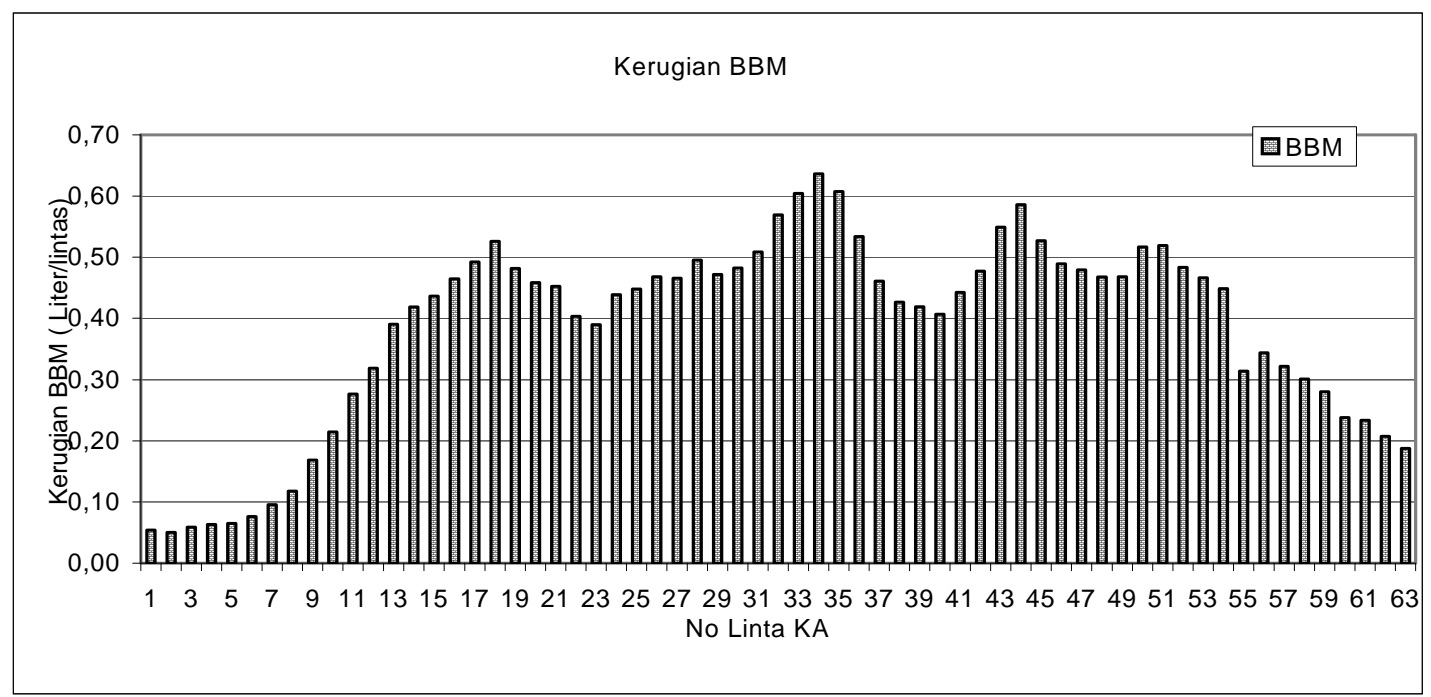

\section{Gambar 4. Kerugian bahan bakar minyak akibat adanya lintasasan kereta Api sebanyak.}

Gambar 4 menunjukan kerugian bahan bakar minyak akibat adanya lintasasan kereta api lalulintas 2 arah (ke Utara dan Selatan) sebanyak $=14,92+9,35=24,27$ liter/hari. Dalam 1 tahun = 24,27 liter $x 360$ hari = 8737,2 liter/tahun. Kerugian kerugian bahan bakar minyak akibat adanya lintasasan kereta Api setiap tahun bila dalam rupiah adalah $=8737,2$ liter $\mathrm{x}$ Rp. 4.500,00 = Rp. 39.317.400,00. Kerugian waktu dan bahan bakar minyak akibat lintasan kereta api sebidang setiap tahun adalah $=$ Rp. 3.485.815.400,00 (tiga milyar empat ratus delapan puluh lima juta delapan ratus lima belas ribu rupiah).

\section{KESIMPULAN}

Penelitian Pegaruh Lintasan Kereta api Terhadap Lalulintas Jalan Urip Sumoharjo Surakarta dapat disimpulkan sebagai berikut:

1. Tingkat pelayanan Jalan Urip Sumoharjo rata-rata C dan B. Tingkat kepadatan pada waktu siang hari antara 68,3 sampai 112,4 kend/km, pada waktu malam hari antara 12,2 sampai $69 \mathrm{kend} / \mathrm{km}$. 
2. Besar tundaan (delay) saat kereta api melintas pada lintasan Jalan Urip Sumoharjo Panggung rata-rata tundaan 178,85 detik.

3. Jumlah antrian pada saat kereta api melintas pada lintasan di Jalan Urip Sumoharja ke arah Utara jumlah antrian rata-rata 36,5 smp tiap lintasan sedang ke arah Selatan jumlah antrian rata-rata 39,0 smp tiap lintasan.

4. Jumlah Tundaan Dua Arah ke Utara dan Selatan 239,34 smp jam/hari dan dalam satu tahun $=86162,4$ smp jam/tahun.

5. Besar kerugian yang ditanggung para pengguna bila waktu dinilai dengan uang pada saat kereta api melintas pada lintasan di Jalan Urip Sumoharjo Panggung dalam 1 Tahun Akibat Lintasan Kereta Api sebesar Rp. 3.446.498.000,00/tahun.

6. Kerugian kerugian bahan bakar minyak akibat adanya lintasan kereta api setiap tahun bila dalam rupiah Rp. 39.317.400,00/tahun. Kerugian waktu dan bahan bakar minyak akibat lintasan kereta api sebidang setiap tahun adalah $=$ Rp. 3.485.815.400,00/tahun (tiga milyar empat ratus delapan puluh lima juta delapan ratus lima belas ribu empat ratus rupiah/tahun).

7. Dalam kurun waktu 10 tahun Kerugian waktu dan bahan bakar minyak akibat lintasan kereta api sebidang setiap tahun adalah $=$ Rp. 34.858.154.000/tahun (tiga puluh empat milyar delapan ratus lima puluh delapan juta seratus lima puluh empat ribu rupiah/10tahun). Sehingga sudah saatnya pada perlintasan dibangun Fly Over.

8. Dalam satu tahun mengalami tundaan akibat kereta api sebanyak $=86162.4 \mathrm{smp}$ jam/tahun, kerugian waktu sebesar Rp. 3.446.498.000,00/tahun, kerugian BBM Rp. 39.317.400,00/tahun, kerugian waktu dan BBM sebesar Rp. 3.485.815.400,00/tahun, dalam kurun waktu 10 tahun sebanyak Rp. 34.858.154.000,00/10 tahun. Sehingga sudah saatnya pada perlintasan dibangun Fly Over.

\section{DAFTAR PUSTAKA}

1.

.1990. Peraturan pemerintah No. 22 Tentang Penyerahan Sebagian

Urusan Pemerintah Dalam Bidang lalulintas dan Angkuta, Dati I dan dati II, Jakarta.

2. .1993. Peraturan pemerintah No. 41 Tentang Lalulintas dan Angkutan, Jakarta.

3. 1993. Peraturan pemerintah No. 43 Tentang Prasarana dan Lalulintas Jalan, Jakarta.

4. .1997. Perencanaan Transportasi, penerbit ITB Bandung. 
5. 1996. Sistem Transportasi, penerbit Universitas Guna Darma Jakarta.

6. Departemen Perhubungan. 1992. Undang-undang lalulintas dan angkutan jalan No. 14 tahun1992, Sinar Grafika Jakarta.

7. Departemen Perhubungan. 1993. Undang-undang lalulintas dan angkutan jalan No. 43 tahun 1992, Dirjen Perhubungan Darat, dicetak oleh yayasan telapak jalan Tebet Timur VII/6A Jakarta.

8. Departemen Perhubungan. 1996. Manual Kapasitas Jalan Indonesia, PT Bina Karya Jakarta.

9. Abubakar. 1996. Menuju Lalulintas dan Angkutan jalan yang Tertip, Direktorat Perhubungan Darat, Jakarta.

10. Nasution,H. 1996, Manejemen Transportasi, Ghalia Indonesia, Jakarta.

11. Prayogo. 1999, Pengaruh lama Penutupan Pintu Lintasan Kereta Api terhadap Tundaan Dan Panjang antrian, Theses S-2 MSTT UGM, Yogyakarta.

12. Tamim,O.Z. 1997, Perencanaan dan Permodelan Transportasi, Penerbit ITB Bandung.

13. Warpani, S. 1990,” Merencanakan Sistem Perangkutan”, Penerbit ITB Bandung. 